\title{
The role of Virtual Globes in geoscience
}

One of the difficulties faced by Earth scientists of all disciplines is how to effectively communicate their research to both other scientists and the general public. With increased attention paid to the health of the planet, the activities of geoscientists in particular are falling under the spotlight of public interest. Whether they are studying the structure of a regional fault system, global weather patterns, the coverage of a continental ice-cap or the localized effects of a seismic event, all face the challenge of how to convey the scale and geospatial distribution of their results. In age where the internet availability has brought an expectation of information being instantly visible in a graphically rich format, the development of Virtual Globes-computer-based representations of the real-world-has become a natural progression for how best to view these data.

The idea that computers could be used to model a Virtual Earth or Globe is as old as the internet itself. Buckminster Fuller's 1962 concept of a Geoscope and MIT's Aspen Movie Map multimedia project in the 1970s were both forerunners for the actual development of an interactive, computer-based model of the entire planet. The key concept for these Virtual Globes is that they are attempts to display the real-world, either as a "mirror" of what we see in daily life or as specialized displays of social, economic, infrastructure or environmental data.

Among those to first be successful in turning dreams into reality were Mark Pesce a co-creator of Virtual Reality Modeling Language (VRML) who used VRML to build "WebEarth" a model of the Earth from composite satellite images and Matt Giger who in 1998 released "Planet Earth" (later renamed to EarthBrowser). The latter was the first commercially available Virtual Globe to display dynamically updated Earth data (clouds). However, it took a confluence of technological development and data availability for Virtual Globe programs to evoke computer industry-wide interest and subsequently enter the public consciousness.

The launches of the Ikonos (1999) and Quickbird (2001) satellites ushered in a new era of Earth imagery acquisition. Through these platforms data with a spatial resolution of a few meters and less became commercially available. At the same time the demands of the gaming community had led to the development of high performance graphics cards becoming part of desktop computer systems. Meanwhile, the late 1990s growth of the internet required a global explosion in broadband internet to keep up with public demands of world-wide-web access without the slow speed and telephone line disruption of using dial-up. These technological advances created a user base that enabled Virtual Globes to become a desktop reality.

The development of Virtual Globes took off in 2001 with several startup companies producing applications. Among them was "EarthViewer" from Keyhole, Inc., who would later (2004) be acquired by Google and EarthViewer was re-packaged as "Google Earth". Although other globes (most notably NASA World Wind released in 2004) illustrated the potential user interest and versatile possibilities for these applications; it was Google Earth that brought Virtual Globes to world-wide attention. In less than five years the application has been downloaded over 500 million times and has become an accepted part of our everyday lives.

One of the reasons for Google Earth's success is that it provides more than just a model of the Earth with images and terrain data. Through Keyhole Markup Language (KML) it offers users the capability to visualize, locate and navigate through their own geospatial data. In $2008 \mathrm{KML}$ became an Open Geospatial Consortium (OGC) standard and whilst not the only language used to create objects in Virtual Globes it has been the most widely embraced by scientific users as a means to create dynamic, interactive displays without the need to be GIS experts or computer programmers. This acceptance is demonstrated by the fact that most of the papers in this special issue discuss a use of KML in some capacity.

The inspiration and interest in the instigation of this special issue grew out of a series of sessions ran at the annual Fall meeting of the American Geophysical Union (AGU) from 2006 to 2009. In total nearly 200 different presentations highlighted scientific uses of KML, Virtual Globes and other geobrowser applications. These sessions brought researchers and educators from different subject fields together through a common interest in this technology. They also provided an opportunity for industry developers and the academic community to meet and interact, thus helping shape the future development of these applications. Most importantly these sessions helped open the eyes of other geoscientists to the possibilities offered by Virtual Globes. It is now almost impossible to attend a conference without seeing multiple instances of slides or posters displaying screenshots from one or more Virtual Globe applications.

In this special issue we bring together a cross-selection of the many examples of how Virtual Globe technologies are being used for geoscience. The first half of the issue focuses on implementations in specific Earth science subjects (atmospheric studies, volcanology, hydrology, seismology). The second half considers broader issues, along with tools and methods applicable to a range of topics. However, several of these papers also focus in author's area of interest to provide Earth science examples (in the fields of glaciology, hydrology, natural hazards and geology).

The first two papers represent one of the original and most obvious scientific uses for Virtual Globes to visualize weather 
patterns. Smith and Lakshmanan use KML as framework for severe weather threat analysis and discuss the relative merits and limitations of Virtual Globes clients for conveying this information. Turk et al. focus on the tracking of tropical cyclones with an application that provides over a decade of archived data and imagery. These are followed by Webley who also considers atmospheric processes as they relate to models of volcanic ash dispersion. He includes an example of how Google Earth can be used to demonstrate the potential hazard of volcanic ash to air traffic.

Two papers then describe the use of KML to visualize the results of ground-based geophysical modeling. Chien and Tan describe KML outputs from the AnuGA hydrodynamic model, whilst also considering the limited potential of Google Earth to offer input data by manually saving KML objects created by a user within the application. Postpischl et al. use KML for seismic data. Specifically they have created repositories that demonstrate (i) a range of tomographic models and (ii) European tensor data for earthquakes from 1997 to the present. These papers are followed by Ballagh et al., who explore the wider picture of both the possibilities and challenges for scientists looking to use KML to visualize their data. They illustrate their thoughts using examples from the National Snow and Ice Data Center.

The next two papers focus on methods and tools rather than specific scientific datasets. Chiang et al. describe a new library (WKML) for Fortran programmers who wish to harness the power of KML. To illustrate WKML they use case studies from the field of hydrology. Bernardin et al. recognize one of the current main shortcomings of Virtual Globes, the lack of control over the base topographic data and offer their own solution. They have developed Crusta as an alternative Virtual Globe that allows users to customize model's topography and imagery, whilst able to view the data on a range of scale, from laptops to immersive geowalls or caves.

The final three papers in this volume consider Virtual Globes as interfaces for the assimilation of data. Tomaszewski describes how they are a natural fit for supporting situation awareness in disaster management as they intrinsically represent dynamic data in space and time. Heavner at al. describe SEAMONSTER-The SouthEast Alaska MOnitoring Network for Science, Telecommunications, Education and Research-which operates a sensor web within partially glaciated watersheds and places the data online coupled with Virtual Earth technology. The volume is completed by De Paor and Whitmeyer, who describe a collection of techniques and methods through which KML can be used to display geological and geophysical data. In particular, they make innovative use of the COLLADA format supported by the Google Earth to create dynamic models that illustrate the internal structure of the planet.

This special issue brings together a small but diverse selection of examples showing how Virtual Globes have become an important and everyday tool for geoscientists. In his 1992 novel "Snow Crash" Neal Stephenson envisioned a protagonist who accesses a software program called "Earth" that was created by the Central Intelligence Corporation (CIC) as a user interface to their geospatial information including weather data and real-time satellite surveillance. This "live action" virtual globe presents greater capabilities than may ever be possible in our desktop Virtual Globes but their dynamic capabilities of these applications have only just started to mature, bringing a way of visualizing our planet that was once the realm of science fiction into the world of real Earth science.

The guest editors would like to acknowledge the hard work and contributions of all the authors, reviewers and the CAGEO editorial staff who contributed to this special issue. We would also like to thank Michael Weiss-Malik, Jon Dehn, Dina Venezky, Ron Schott, Glenn Richard, Rich Treves, Mano Marks and the hundreds of scientists, educators and developers who have contributed to the organization and success of the AGU sessions that inspired this volume and continue to evolve the application of Virtual Globes in the geosciences.

John E. Bailey* Scenarios Network for Alaska and Arctic Planning (SNAP), University of Alaska Fairbanks, 3352, College Road, Fairbanks, AK 99709, USA E-mail address: geobrowser@gmail.com

Aijun Chen

Goddard Earth Sciences Data and Information Services Center (GES DISC), NASA Goddard Space Flight Center, Code 610.2, Greenbelt, MD 20771, USA E-mail address: aijunchen@gmail.com

31 May 2010 